\title{
VULNERACIÓN DE DERECHOS HUMANOS DE LÍDERES \\ SOCIALES Y DEFENSORES DE DERECHOS HUMANOS EN COLOMBIA, 2015-2019
}

\section{VIOLATION OF HUMAN RIGHTS OF SOCIAL LEADERS AND DEFENDERS OF HUMAN RIGHTS IN COLOMBIA, 2015-2019 \\ VIOLAÇÃO DOS DIREITOS HUMANOS DE LÍDERES SOCIAIS E DEFENSORES DE DIREITOS HUMANOS NA COLÔMBIA, 2015-2019}

\section{Samuel Melo Balcázar}

¿Cómo citar este artículo?:

Melo Balcázar, S. (2021). Vulneración de derechos humanos de líderes sociales y defensores de derechos humanos en Colombia, 2015-2019. Cultura Científica, 19, pp. 36-58.

https://doi.org/10.38017/1657463X.705

1 Politólogo en formación de la Universidad del Cauca. samuelmeloba@unicauca.edu.co. https://orcid.org/0000-0003-0900-2152. 


\section{RESUMEN}

Se analizó comparativamente la vulneración de los derechos humanos (DDHH) a los líderes sociales y defensores en el territorio colombiano entre los años 2015 y 2019. Para ello, se utilizaron los métodos estadístico e historiográfico para realizar un análisis de datos agregados y una revisión documental, teniendo como fuentes distintas organizaciones sociales y algunas instituciones estatales. De esta manera, se problematizó la conceptualización de las categorías de líder social y defensor de DDHH para comparar las diferencias entre las definiciones propuestas por el Estado y las organizaciones no estatales. Se cuantificaron las vulneraciones como amenaza, asesinato, atentados, detenciones arbitrarias, judicializaciones, desapariciones, uso arbitrario del sistema penal y hurto de información para ver la magnitud de la problemática en el periodo de estudio. Finalmente se concluyó que el Estado no ha mitigado la vulneración de derechos humanos a defensores y a líderes sociales, con lo que la problemática se agudiza en los territorios, lo que profundiza las carencias en aspectos sociales y las desigualdades que presenta el país.

Palabras claves: Colombia; conflicto armado; defensor de derechos humanos; líder social; política pública.

\section{ABSTRACT}

A comparative analysis was carried out on the violation of human rights (HR) of social leaders and defenders in the Colombian territory between the years 2015 and 2019. For this purpose, the statistical and historiographic methods were used to perform an analysis of added data and a documentary review, having as sources different social organizations and some state institutions. In this way, the conceptualization of the categories of social leader and human rights defender was questioned to compare the differences between the definitions proposed by the State and nonState organizations. Infringements such as threats, assassinations, attacks, arbitrary detentions, prosecutions, disappearances, arbitrary use of the penal system, and theft of information were quantified to see the magnitude of the problem in the study period. Finally, it was concluded that the State has not mitigated the violation of the human rights of defenders and social leaders, thus exacerbating the problem in the territories, which worsens the deficiencies in social aspects and inequalities in the country.

Keywords: Colombia; armed conflict; human rights defender; social leader; public policy. 


\section{RESUMO}

Analisou-se comparativamente a violação dos direitos humanos dos líderes sociais e de seus defensores no território colombiano entre 2015 e 2019. Para isso, foram utilizados métodos estatísticos e historiográficos para realizar uma análise de dados agregados e uma revisão documental, tendo como fontes diferentes organizações sociais e algumas instituições estatais. Dessa forma, a conceituação das categorias de líder social e defensor dos direitos humanos tem sido questionada para comparar as diferenças entre elas do Estado e do não-Estado. Posteriormente, as violações foram quantificadas como ameaça, assassinato, ataques, prisões arbitrárias, processos, desaparecimentos, uso arbitrário do sistema penal e roubo de informações para ver a magnitude do problema no período do estudo. Por fim, concluiu-se que o Estado não atenuou o problema subjacente da violação dos direitos humanos contra defensores e líderes sociais, agravando o problema nos territórios, aprofundando as deficiências em aspectos sociais e aprofundando as desigualdades que apresenta o país.

Palavras chaves: Colômbia; conflito armado; defensor dos direitos humanos; líder sociais 


\section{INTRODUCCIÓN}

En Colombia, el goce y respeto por los derechos humanos es una práctica que se ha deteriorado progresivamente, por lo menos desde finales de la década de los setenta. El autoritarismo y la violencia hacia detractores políticos han sido una práctica que se ha presentado en el país por muchos años, desde Turbay Ayala (1978-1982), por ejemplo, cuando se le acusaba de tener presos políticos (Rojas, 2001) en el marco del Estatuto de Seguridad. Desde Turbay Ayala hasta los años recientes han sido constante las formas autoritarias a la hora de gobernar, como lo ha sido la estigmatización contra quienes piensan diferente al establecimiento.

Es lamentable que se requieran defensores de los derechos humanos, aquellos que son fundamentales para las comunidades a lo largo y ancho de la periferia nacional. Esta necesidad es consecuencia de tres factores fundamentales que deben presentarse en un territorio en concreto: el primero es que haya un abandono estatal del territorio, donde su presencia sea débil; el segundo es que exista un actor armado irregular -guerrilla o grupo paramilitar- que sea factor de terror localmente y victimice amenazando, violando, asesinando, hurtando información, desapareciendo a personas, entre otros hechos victimizantes; el tercero es alguien que se empodera y defienda el bienestar común localmente, que luche por lo propio y lo ajeno.
Esto puede verse en la ruralidad de Colombia, donde lo único abundante es la pobreza y los problemas generados por los actores armados irregulares que expanden el miedo, las injusticias y la desigualdad, allí donde el Estado ha sido diferenciado, donde hay instituciones tanto modernas como tradicionales -relaciones clientelares, partidos tradicionales, grupos armados. Los distintos poderes enfrentados en la ruralidad- (González González, 2014; González González y Otero Bahamón, 2006), gracias al abandono que históricamente se ha tenido en estos lugares. Precisamente ahí es donde están los líderes y lideresas sociales y defensores de derechos humanos, por ello hay que resolver tres inquietudes: ¿qué es un líder social?, ¿qué diferencia hay entre un líder social y un defensor de derechos humanos?, y ¿cuáles son las victimizaciones que sufren? A continuación, se desarrollan dichos cuestionamientos.

La primera inquietud por responder cuando se habla sobre la vulneración a los derechos humanos a los líderes y lideresas sociales en Colombia es precisamente qué es un líder social. Este concepto es completamente variopinto, puesto que las organizaciones lo ven de una manera y el Estado de otra. Precisamente esta variedad de definiciones es lo que lleva a que, por un lado, los programas que intenta desarrollar el gobierno nacional no cumplan con su objetivo de proteger la vida de estas personas $y$, por otro, que el conteo de personas a las que se les vulneran los DDHH
En Colombia, el goce $y$ respeto por los derechos humanos es una práctica que se ha deteriorado progresivamente, por lo menos desde finales de la década de los setenta. 
"quien ejerce

liderazgo, éste es la función de dinamización de un grupo o de una organización para su desarrollo en base a un proyecto común o un proyecto compartido" sea diferente, dependiendo siempre de quién realice la medición. Así las cosas, para ver lo complejo que puede ser definir a un líder social en Colombia, se revisarán, de manera breve, algunas definiciones, unas más complejas que otras, para ampliar dicha visión.

Para el Instituto de Estudios Políticos y Relaciones Internacionales -IEPRI- (2018) es claro que los líderes sociales en el país los define su trabajo en una comunidad y obtienen de la misma una legitimidad sobre sus actos por "conducir, coordinar o apoyar procesos o actividades de carácter colectivo que afectan positivamente la vida de su comunidad, mejoran y dignifican sus condiciones de vida o construyen tejido social" (p. 10). Con esta visión se puede fortalecer el imaginario que se tiene de un líder social, que es alguien que trabaja por la comunidad $y$, por esa misma razón, puede ser cualquier persona que quiera solucionar problemas en el lugar donde vive.

Por otro lado, Estrada Jopia (2009) los define como "quien ejerce liderazgo, éste es la función de dinamización de un grupo o de una organización para su desarrollo en base a un proyecto común o un proyecto compartido" (pár. 4). Además, menciona que debe ser alguien con formación académica suficiente para llevar a cabo proyectos que benefician a la comunidad en la que viven, pero también "de empoderar a otros, de formar nuevos líderes, de transferir lo que está haciendo para que otros líderes en otras situaciones puedan ejercer un nuevo liderazgo" (pár. 4). Esta definición excluye a quienes no tiene formación académica, pero sí conocen bien los problemas sociales del territorio.

En este sentido, la organización Somos Defensores, que es una agrupación de organizaciones no gubernamentales que busca realizar una propuesta para prevenir agresiones y proteger la vida de defensores, además de contar con un sistema de medición sobre vulneraciones a DDHH fiable, muestra qué categorías hacen parte de la definición de líder o lideresa social. En este sentido, propone que un líder social puede ser cualquiera que defienda la causa de un territorio, una causa común. Para esta organización, al momento de contabilizar cuántos líderes sociales han tenido vulneración a sus derechos humanos hay que abarcar al líder comunal, sindical, indígena, afrodescendiente, campesino, educativo, de restitución de tierras, entre otros que desarrollan una labor similar.

Por otra parte, Carreras (en Carreras, Leaverton y Sureda, 2009) menciona que "el concepto de liderazgo social está asociado a la trayectoria de personas impulsoras de organizaciones de la sociedad civil que actúan con una vocación de transformación social” (p. 14). Se agrega que es un concepto en construcción. También menciona que estas personas pueden estar institucionalizadas en una organización o asociación que lleve a cabo estas acciones o de manera individual. Esto que es adicional a las visiones presentadas previamente es útil, puesto que el Estado colombiano no menciona en su definición a los 
líderes y defensores que no hacen parte de ninguna institución, con lo que se estaría, por un lado, reduciendo la cantidad total de quienes hacen parte del inmenso grupo de los que son líderes sociales y, por otro, promoviendo la injusticia -o siendo injustos- con las personas que desde el anonimato absoluto y que, por vocación, desarrollan actividades por su territorio.

En este orden de ideas, el Estado colombiano tiene la mayor cantidad de subcategorías en el concepto de líder social, mas no da una definición concreta:

líder comunal, líder comunitario, líder de Restitución de Tierras, líder campesino, líder social, líder sindical, líder ambiental, líder de mujeres, líder afrodescendiente, líder indígena, líder de víctimas o de desplazados, líder juvenil y de la infancia, líder cultural, líder LGBTI, líder en salud, líder minero artesanal, comunicador defensor de derechos humanos, abogado defensor de los derechos humanos, defensor o líder asociado a Organizaciones no Gubernamentales (ONG), líder en la implementación del acuerdo de paz, líder en materia de sustitución de cultivos, líder de movimiento político y líderes religiosos (Consejería Presidencial para los Derechos Humanos y los Asuntos Internacionales, 2019, p.10).

Además, el Estado se adhiere a la definición suscrita por las Naciones Unidas, que indica que:

La persona que actúe en favor de un derecho (o varios derechos) humano(s) de un individuo o un grupo será un defensor de los derechos humanos. Estas personas se esfuerzan en promover y proteger los derechos civiles y políticos y en lograr la promoción, la protección y el disfrute de los derechos económicos, sociales y culturales (p. 10).

Un líder social y un defensor de derechos humanos no son necesariamente las mismas personas, es decir, un líder social es, o puede ser, un defensor de DDHH, este último no necesariamente es un líder social, ya que la característica central que tienen los líderes es una vocación de apoyar a su comunidad en distintos escenarios: en lo político, en lo comunitario, lo ambiental, en salud, entre otros. Son personas que buscan la transformación social en el lugar donde viven (Salazar y Gómez, 2019, pár. 7). Por su parte, la Organización Nacional Indígena de Colombia -ONIC- menciona que ser reconocido como tal es un privilegio, puesto que lo que ellos hacen es "remangarse las mangas y trabajar por un país mejor y hacerlo real, no solamente quedarse desde la barrera viendo como otros construyen el futuro" (Ramírez León, 2017, pár. 4), por lo que tienen función de tramitar distintas problemáticas para darle solución, como se mencionó anteriormente.

Por otra parte, para la Comisión Interamericana de Derechos Humanos -CIDH-, un defensor de DDHH es "toda persona que de cualquier forma promueva o procure la realización de los derechos humanos y las libertades fundamentales reconocidos a nivel nacional o internacional” (CIDH, 2019a, 2019b, p. 21). Es decir, un líder social puede ser un defensor de DDHH. La diferencia radica en que el líder social

\author{
La persona que \\ actúe en favor de \\ un derecho \\ (o varios \\ derechos) \\ humano(s) de \\ un individuo o un \\ grupo será \\ un defensor de \\ los derechos \\ humanos.
}


lleva a cabo distintas acciones que buscan beneficiar a su comunidad, como ya se mencionó. Ahora bien, en el transcurso de estas acciones terminan defendiendo DDHH y derechos fundamentales, por lo que también cabrían en esta definición de defensor de DDHH. La defensa de los derechos humanos es transversal al actuar de los líderes sociales, pero las acciones de los líderes sociales no son llevadas a cabo necesariamente por los defensores de DDHH directamente. Esta es la razón por la cual son dos categorías distintas, aunque ambas pueden estar presentes en un mismo territorio y convivir.

Ahora bien, el problema es, entonces, que ante la falta de consenso sobre lo que es un líder social $-y$ ante el sesgo del Estado colombiano para tener una visibilización amplia de estos, que puede ser por un tema de imposibilidad institucional para proteger o cobijar a todos ellos- se hace compleja la prevención y protección a los líderes sociales. A ello se suma un inconveniente práctico, y es que no se sabe ni cuántos son, ni dónde están, lo que supone una gran dificultad institucional, en teoría, porque no se sabría a quién debe protegerse.

El periodo de estudio fue entre el 2015-2019. En esta temporalidad se presentó una transición entre dos gobiernos: final del segundo gobierno de Juan Manuel Santos (2014-2018) y comienzo del gobierno de Iván Duque (2018-2022). Las diferencias existentes entre ambos gobiernos en cuanto a la implementación del acuerdo de paz han sido fundamentales para entender la defensa de los DDHH a los líderes sociales en los territorios marcados por la guerra y ahora 'baldíos' ante la ausencia de la extinta guerrilla de las Fuerzas Armadas Revolucionarias de Colombia -FARC- $u$ ocupados por el Ejército de Liberación Nacional -ELN-. Esto porque la implementación de los acuerdos de paz permite que haya una atención desde el Estado con lo rural, lo que permite acabar con los factores que inciden en la violencia que se vive: el abandono estatal, la pobreza, incluso el narcotráfico -toda vez que este resulta en la solución a problemas económicos de los lugareños, antes que un asunto vocacional en la zona-.

Este evento político es importante, puesto que la forma discursiva en que es tratado este tema desde lo gubernamental ha sido negacionista, lo que significa que para la institucionalidad no hay problemas en los territorios, no hay violación de derechos humanos y el conflicto armado no existió -fue una amenaza terrorista contra el Estado-. Por lo tanto, el aumento de la violencia sufrida por defensores de DDHH y líderes sociales ha tenido cabida a lo largo y ancho del territorio, ya que:

La aparición de Iván Duque en las candidaturas presidenciales con una alta favorabilidad reforzó esta posibilidad, no solo representaba la perpetuación de la clase política tradicional que ha gobernado a Colombia durante décadas, con él también surgía el riesgo de volver inviable cualquier intento de construcción de paz (Somos Defensores, 2019a, p. 37). 
Es destacable que en Colombia los líderes, lideresas y defensores de DDHH se han visto afectados por el aumento en los asesinatos, amenazas y distintas vulneraciones a sus derechos, a pesar de que el Estado minimice esta situación y diga adelantar esfuerzos para su defensa, como lo menciona Somos Defensores (2017, 2018a, 2018b, 2019a, 2019b). Cabe recordar que los hechos victimizantes perpetrados hacia los líderes y lideresas sociales están catalogadas en 8 variables por Somos Defensores, de la misma forma que en este artículo, los cuales son: amenaza, asesinato, atentados, detenciones arbitrarias, judicializaciones, desapariciones, uso arbitrario del sistema penal y hurto de información.

En primer lugar, y teniendo claras las tres interrogantes anteriormente presentadas, se observaron las acciones implementadas por el Estado para la defensa de los líderes sociales y defensores de DDHH, y los datos disponibles para problematizar la efectividad de estas acciones, a grandes rasgos. En segundo lugar, se parte de las cifras de organizaciones y de la institucionalidad para analizarlas con notas periodísticas y fuentes oficiales, para exponer algunos motivos por los que las cifras son distintas entre las fuentes. Por último, se observa que, a pesar de la labor tan importante que tiene los líderes, siguen siendo vulnerados sus DDHH, a pesar de los esfuerzos estatales, con el agravante de la ambigüedad de un concepto sobre lo que son, ya que es tan amplio que el mismo Estado ha sido incapaz de brindar acciones adecuadas para la protección de estas personas.

\section{METOdOLOGÍA}

Se analizó la vulneración de DDHH en el país en contra de los líderes sociales y defensores de DDHH entre los años 2015-2019 con un uso mixto de metodologías. Se utilizaron el método estadístico y el método historiográfico, ambos complementarios para entender la realidad social en cualquier territorio. Estadísticamente se analizaron datos agregados de distintas fuentes institucionales, estatales y no estatales, con el fin de obtener un amplio panorama sobre las cifras existentes, teniendo en cuenta las variables que las fuentes presentan. Las fuentes fueron Somos Defensores, ${ }^{2}$ el Observatorio de Derechos Humanos de la Vicepresidencia de la República y fuentes académicas para tener una visión amplia en este análisis.

Por otra parte, se utilizó la técnica de análisis documental, del método historiográfico, para la revisión de fuentes noticiosas, tales como El Espectador, la Revista Semana, Pacifista, en las secciones sobre conflicto armado. También fue útil para inspeccionar fuentes oficiales como el Congreso de la República

2 Esta ONG se ha encargado de estudiar estas vulneraciones de muy buena manera, puesto que la larga trayectoria de defensa de los DDHH de líderes sociales y defensores le da una legitimidad muy importante y crucial para esta investigación al poseer datos históricos que permiten monitorear esta problemática. 
y el Observatorio de Derechos Humanos de la Vicepresidencia de la República. Con lo anterior, se puede observar la cobertura que desde medios de comunicación se les ha dado a las vulneraciones de DDHH a los líderes y defensores y la respuesta desde el Estado, esto mediante la expedición de distintas leyes. De esta manera, se ha podido establecer un panorama de la situación del país sobre estas vulneraciones: que se presentan por ser líderes sociales, por defender la paz o la implementación de los acuerdos de paz, o por defender los derechos de una comunidad.

\section{RESULTADOS}

La protección a los líderes sociales en el país es un tema por atender de manera urgente, puesto que hay una tendencia creciente a la vulneración de derechos humanos. Razón por la cual el Estado colombiano debe aplicar correctivos en cuanto a la prevención y protección de líderes y defensores, ya que las normatividades hechas por los distintos gobiernos no han tenido éxito.

El actuar del Estado, en temas de $\mathrm{DDHH}$, nunca ha sido de manera preventiva. Es decir, no es por un genuino sentir de preocupación por quienes desarrollan estas labores fundamentales para los territorios, sino por presiones y ante escenarios lamentables de genocidio o asesinato sistemático de defensores de los intereses de las comunidades.

Ahora bien, en el país se han venido implementado una serie de leyes y decretos que buscan crear los programas de protección para quienes son líderes y defensores de DDHH. Las legislaciones y en qué consisten, grosso modo, teniendo como punto de partida lo que dice la Consejería Presidencial para los Derechos Humanos y Asuntos Internacionales (2019) -CPDHAI-, son los siguientes.

- El Decreto 418 de 1997, por la cual se consagran unos instrumentos para la búsqueda de la convivencia, la eficacia de la justicia $y$ se dictan otras disposiciones, obliga al Estado a "poner en funcionamiento un programa de protección a personas que se encuentren en situación de riesgo contra su vida, integridad, seguridad o libertad, por causas relacionadas con la violencia política o ideológica, o con el conflicto armado interno" (p. 5). Es destacable que, por más que el gobierno niegue el conflicto armado (El Espectador, 2011; Pacifista, 2019; Chaux, 2007, p. 136), la legislación dice que lo hay y obliga a que haya prevención de los casos.

- El Decreto 978 del 2000, el cual tenía como fin proteger a los miembros de los movimientos políticos Unión Patriótica y Partido Comunista, quienes fueron amenazados contra su vida, integridad, libertad o seguridad. Además, tenía "la asistencia humanitaria, la protección a sedes y residencias de los dirigentes, miembros y sobrevivientes de la Unión Patriótica y del Partido Comunista Colombiano, y la protección personal”. Eso ha sucedido 
nuevamente, a pesar de los llamados de la CIDH de reforzar las medidas para garantizar la vida. integridad y seguridad de quienes defienden derechos humanos en el país.

- El Decreto 2788 de 2003, con el que se buscaba crear el Comité de Reglamentación y Evaluación de Riesgos -CRER-, que a su vez tenía la función de evaluar las solicitudes que se presentaban a la Dirección de Derechos Humanos del Ministerio del Interior.

- El Decreto 2816 de 2006, por el cual se diseña y reglamenta el Programa de Protección de Derechos Humanos del Ministerio del Interior $y$ de Justicia $y$ se adoptan otras disposiciones. Este programa era un apoyo para el gobierno nacional en su búsqueda de salvaguardar la vida, integridad y seguridad de una población. A pesar de ello, tiene como población objetivo a personas que están institucionalizadas en alguna organización, bien sea en el Estado colombiano, como diputados, alcaldes, gobernadores, concejales, entre otros funcionarios, o los que han sido parte de otras instituciones estatales, pero no aquellos que no hagan parte de un partido político u organización social. Es una dificultad, dado que un líder social no necesariamente está en una de estas, sino que puede trabajar desde el anonimato, solo con la legitimidad del territorio donde está. Es decir, este decreto tiene la misma visión que en la década de 1990 en la legislación colombiana, en la que "los sujetos de protección son los dirigentes o activistas de grupos políticos y especialmente de grupos de oposición, dirigentes y activistas de las organizaciones de derechos humanos, entre otros." (Observatorio de Derechos Humanos de la Vicepresidencia de la República, 2019. p. 8).

- El Decreto Ley 4530 de 2008, en el numeral 2, da facultad a Ministerio del Interior para formular la política para la participación de la ciudadanía, la seguridad en los territorios, el acceso a la justicia y otras disposiciones. Igualmente, en el 2011 se creó una ley y tres decretos: Ley 1448 por la cual se dictan medidas de atención, asistencia y reparación integral a las víctimas del conflicto armado interno $y$ se dictan otras disposiciones, con el que daría protección a defensores de DDHH. El Decreto 4065 Por el cual se crea la Unidad Nacional de Protección (UNP), se establecen su objetivo $y$ estructura, el cual debe prestar la protección a quien el gobierno nacional, dado el perfil del solicitante, determine darlo. Este detalle es de vital importancia, ya que, si hay un gobierno negacionista del conflicto, también será reacio a brindar la protección. El Decreto 4912 por el cual se organiza el Programa de Prevención y Protección de los derechos a la vida, la libertad, la integridad y la seguridad de personas, grupos y comunidades del Ministerio del Interior y de la Unidad Nacional de Protección. Con este decreto se 
deben dar medidas de protección para las personas que por sus acciones humanitarias, sociales o políticas así lo requieran y debe ser mediante la UNP.

- El Decreto 1314 de 2016, por el cual se crea la Comisión Intersectorial de Garantías para las Mujeres Lideresas y Defensoras de los Derechos Humanos. Este tiene en cuenta que las mujeres que defienden derechos humanos y son lideresas sociales tienen un doble riesgo, puesto que por a su labor de liderar diversos procesos y por ser mujeres, como fruto de la violencia política que se vive en el país y que con el género puede ser mucho más fuerte.

En el año 2017, y con el propósito de legislar para implementar lo acordado con la extinta guerrilla de las FARC, se crearon los siguientes decretos:

- El Decreto 154, por el cual se crea la Comisión Nacional de Garantías de Seguridad en el Marco del Acuerdo Final, suscrito entre el Gobierno Nacional y las FARC-EP el 24 de noviembre de 2016.

- El Decreto 1581, Por el cual se adiciona el Título 3 a la Parte 4, del Libro 2 del Decreto 1066 de 2015, Decreto Único Reglamentario del Sector Administrativo del Interior, para adoptar la política pública de prevención de violaciones a los derechos a la vida, integridad, libertad y seguridad de personas, grupos y comunidades, y se dictan otras disposiciones-.
- El Decreto 2078, Por el cual se adiciona el Capítulo 5, del Título 1, de la Parte 4, del Libro 2 del Decreto 1066 de 2015, Decreto Único Reglamentario del Sector Administrativo del Interior, sobre la ruta de protección colectiva de los derechos a la vida, la libertad, la integridad y la seguridad personal de grupos y comunidades.

- El Decreto 2137 del 2018 creó el PAO -Plan de Acción Oportuna-, con el cual se busca prevenir y proteger a líderes sociales, comunales y periodistas. Está conformado por ministros y directores de la Policía y la UNP, mas no de la Defensoría del Pueblo, que recibe estas denuncias. Aunque hay una normatividad para la protección de líderes y defensores, hay a la par un aumento en las violencias vividas por estos actores.

De todo lo anterior es visible que los líderes sociales y defensores de DDHH son de gran importancia para el país en los distintos territorios. Aunque desde el Estado se ha pretendido mitigar el problema mediante leyes y decretos, que buscan la creación de instituciones o la modificación de estas para proteger los derechos de las líderes y lideresas sociales y defensores de $\mathrm{DDHH}$, las cifras muestran que este es un objetivo lejano de cumplir, esto lo evidencia Somos Defensores (2018a, 2018b, 2019a, 2019b) en sus informes.

Las categorías de hechos victimizantes hacia líderes sociales y defensores de DDHH son: amenaza, asesinato, atentados, detenciones 
arbitrarias, judicializaciones, desapariciones, uso arbitrario del sistema penal y hurto de información. Estas han sido llevadas a cabo de manera constante a lo largo del periodo estudiado -2015-2019-.
Las amenazas son una constante durante los cinco años (figura 1), a diferencia de otros hechos que han aparecido en otros momentos $y$ que tienen un peso menor en todos los hechos.

Figura 1. Hechos victimizantes hacia líderes y lideresas sociales en Colombia, 2015-20193

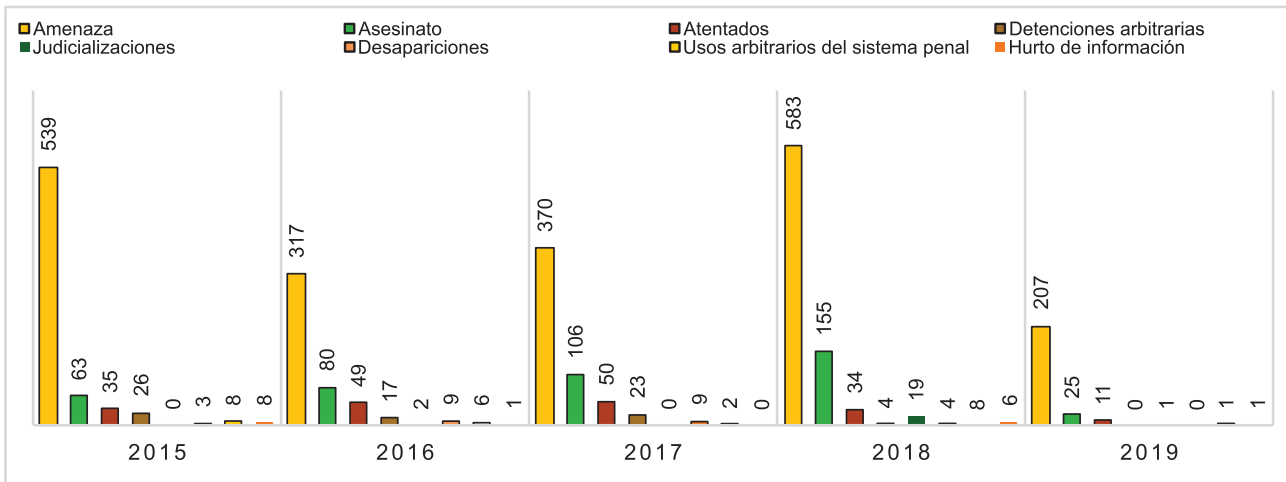

Fuente: Somos Defensores (2017, 2018a, 2018b, 2019a, 2019b). Elaboración propia.

Todos los hechos victimizantes mencionados anteriormente afectan a toda una variedad de líderes. Con este perfil tan variopinto que se presenta puede verse de manera aún más evidente que los problemas del país responden a la sumatoria de múltiples fracciones de la sociedad y que estos líderes pueden ayudar a tramitar sus problemas ante la carencia de instituciones del Estado que cumplan esa función.

Es destacable que, en la realidad que vive Colombia, ser defensor de los derechos humanos o líder social en los distintos territorios a lo largo

3 Las cifras del año 2019 corresponden al Informe del primer trimestre del 2019 publicado por Somos Defensores. Esta organización no tiene publicado datos de otros trimestres del mismo año. y ancho del país, especialmente en la profunda, aislada y sumida en el olvido estatal -el Estado que se conoce tradicionalmente con sus instituciones y una legitimidad legal- representa un gran riesgo, puesto que estos están "librando una lucha doble, por un lado, el trabajo para defender los intereses de sus comunidades y, por el otro, una lucha constante y solitaria para evadir las amenazas que les llegan todo el tiempo y preservar sus vidas" (Somos Defensores, 2019b, p. 47). Con esto, estar inconforme con el rol de las autoridades, exigir que se cumplan los derechos, que el Estado cumpla con su labor, que haya justicia, se convierte en una carrera de muerte, como se verá más adelante (figura 2) al observar cómo el número de líderes sociales que han sido asesinados se ha incrementado. 
Figura 2. Comparación de asesinato de líderes sociales en diferentes organizaciones del país 2016-20194

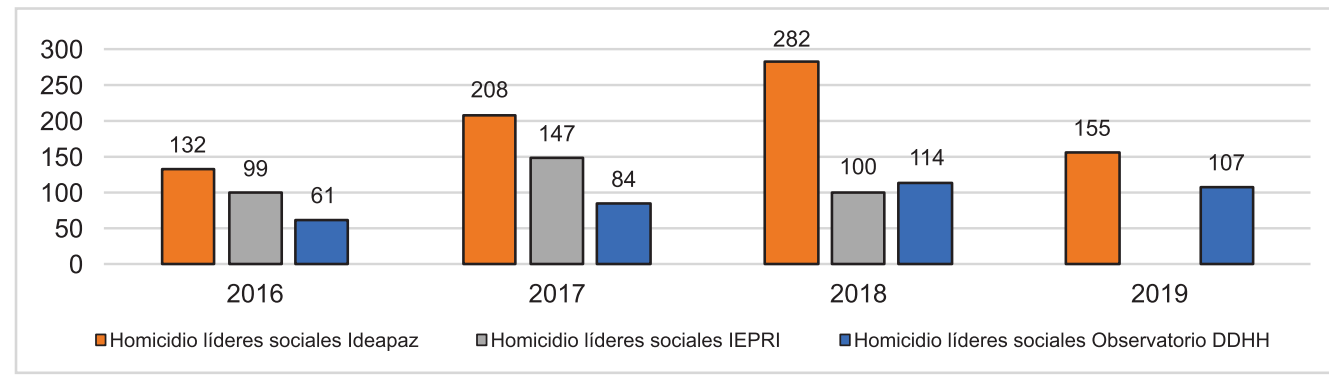

Fuente: Indeapaz (2019) IEPRI (2018) y Observatorio de Derechos Humanos de la Vicepresidencia de la República (2019). Elaboración propia.

En la figura 2 se hace una comparación entre las publicaciones de tres instituciones: el Observatorio de Derechos Humanos de la Vicepresidencia de la República, la fundación Indepaz -Instituto de Estudios para el Desarrollo y la Paz- y el IEPRI. Esto para comparar las cifras publicadas por estas tres instituciones y evidenciar que sucede lo mismo con la definición de líder social: es distinta en cada organismo. No obstante, es destacable que la versión estatal es la que tiene la menor cantidad de datos en tres de los cuatro años estudiados (2015-2019).

La diferencia que se presenta entre los distintos organismos que han medido el asesinato de líderes y lideresas sociales es por los actores que pueden ser considerados así. La plataforma periodística Pacifista (2020) dice que desde la implementación del Acuerdo de paz

4 El IEPRI realizó una investigación hasta el año 2018, razón por la cual no presenta ningún dato en el año 2019, en comparación a las otras dos organizaciones. entre el gobierno y las FARC, en Colombia han asesinado a 277 personas consideradas así, entre las cuales están "dirigentes que van desde presidentes de juntas de acción comunal, miembros de la Guardia Campesina, líderes indígenas, estudiantes, etcétera” (pár. 2).

Con los datos del IEPRI se puede ver la razón por la que se registra una cantidad mayor de personas asesinadas y que son consideradas como líderes sociales. Esta definición es bastante amplia, aunque no dice quiénes están inmersos en esta, a diferencia de las otras organizaciones. Entre las tres, esta dice qué es un líder social, los otros dicen quiénes lo son, es decir, categorías que permiten caracterizar.

Por otra parte, Indepaz (2019) menciona que en 2020 se han asesinado a 112 personas líderes sociales en el territorio nacional, hasta el mes de mayo, ${ }^{5}$ con lo que

5 Este dato tiene como fecha de corte el 27 de mayo de 2020, por consiguiente, este número ha de ser mayor a la fecha de publicación de este artículo. 
se evidencia que quien se puede considerar como líder social es determinante al momento de medir cuántos han asesinado a la fecha. Además, es interesante que la categoría de análisis siempre se presenta como líder social y defensor de derechos humanos, debido a que la defensa estos últimos siempre estará en medio de la labor de todo líder en un territorio, ya que siempre han sido un tema de vital importancia. La defensa de los DDHH en últimas es trasversal a la labor que han desempeñado desde hace mucho tiempo los líderes sociales con los intereses de las distintas comunidades a lo largo y ancho del país.

Es claro que es el gobierno quien tiene una medición más baja de todas las organizaciones -lo que tiene sentido-, porque tiene un afán de disminuir cifras y hacer eco del discurso de negación del conflicto armado interno en Colombia. Por ello, se deja por fuera de los números a una gran cantidad de líderes, dado el número reportado, matando por segunda vez a las comunidades afectadas por la falta de un canal para tramitar sus necesidades, puesto que es un puente que permite el desarrollo en un territorio determinado. De ahí que se diga que el Estado mata a una comunidad entera.

En definitiva, las amenazas y los asesinatos de quienes se encargan de la vocería de problemas en lo profundo del país -donde le Estado ha tenido, incluso, una presencia diferenciada con los grupos armados, los cuales llegan a tener la definición de Estado de Max Weber ${ }^{6}$ - hacen que se llene de miedo a una comunidad, impidiendo que esta pueda superar el pasado oscuro que ha vivido por cuenta del conflicto armado. Por esto, se pueden presentar grandes obstáculos para la superación del conflicto en estos territorios, debido a que se sigue viviendo lo mismo. Esto ha sido un capítulo que no ha tenido cierre, un acápite tenebroso que se sigue escribiendo con la sangre de la población más pobre y vulnerable, los inocentes que han tenido que sufrir una guerra que no debieron, fruto de las grandes desigualdades que han reinado en el país.

En el periodo de estudio hay dos aumentos en el caso de asesinatos de líderes sociales: por un lado, el número de personas asesinadas, que en su mayoría lo han sido por paramilitares o no se ha podido dar claridad sobre quién cometió el hecho; por el otro, hay un aumento en el número de municipios donde se ha presentado, por lo menos, un líder social finado (figura 3). Es decir, están matando a más líderes sociales y en más lugares, muchos de ellos donde hay presencia de cultivos ilícitos, puesto que suelen oponerse a esto (Gómez, 2018).

\footnotetext{
6 Max Weber dice que el Estado "es aquella comunidad humana que, dentro de un determinado territorio (el "territorio" es elemento distintivo), reclama (con éxito) para sí el monopolio de la violencia física legítima." (Weber, 1979, p. 83).
} 
Figura 3. Número de municipios en los que se ha presentado homicidios contra líderes sociales 2016-2019

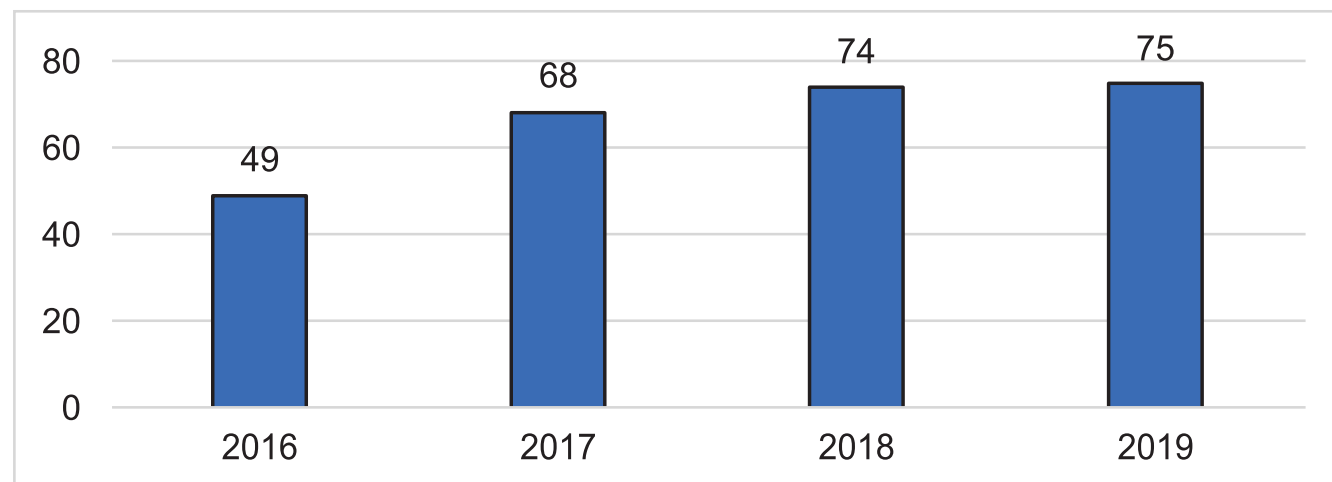

Fuente: Observatorio de Derechos Humanos de la Vicepresidencia de la República (2019). Elaboración propia.

Con la figura anterior se observa que cada vez es más frecuente tener más asesinatos de líderes sociales en más lugares del país. Se pasó de tener 49 municipios en donde se asesina por lo menos a un líder social a tener 75 , en tan solo 4 años, sin tener en cuenta los casos que podrían hacer parte de un subregistro.

Muchos de estos territorios tienen presencia de cultivos de uso ilícito, aunque normalmente son lugares alejados, los cuales tienen el mismo problema que muestra la figura 2 , la disparidad de cifras o el subregistro, puesto que "debido a la dificultad para recolectar información en los lugares donde ocurren estos asesinatos, las cifras presentadas hasta el momento difieren bastante" (Navarrete y Alonso, 2020, pár. 3). Por ejemplo, dicen las mismas autoras que en el Bajo Cauca hay una disputa que desde antes de la firma del Acuerdo final se ha venido llevando a cabo. Hay presencia de guerrilla, el ELN, y de bandas criminales -BACRIM-, los Urabeños y los Caparrapos -una parte de los Urabeños separada-.

Todos estos departamentos donde hay un aumento en el número de asesinatos de líderes sociales hay un avance que es mínimo en el tema de restitución de tierras (El Espectador, 2019). Esto apoyaría la hipótesis de que a los líderes sociales los estaría asesinando el narcotráfico, porque en estos lugares presentan una doble vulneración. Además de ser líderes o defensores, se oponen a cultivos de uso ilícito (Gómez, 2018); aunque las cifras dicen que son los grupos paramilitares quienes cometen los homicidios.

Todo esto tiene como punto de partida que "el Estado colombiano no ha cumplido con lo que les prometió a las comunidades campesinas y étnicas sobre su derecho a la tierra y que el asesinato de líderes no ha 
disminuido” (Semana Rural, 2019, pár. 4). ${ }^{7}$ Esto quiere decir que en el país no hay procesos de restitución de tierras, las que les fueron despojados a los campesinos y que deben ser reintegradas a ellos.

Figura 4. Autores de homicidios de líderes sociales 2015-2019 89

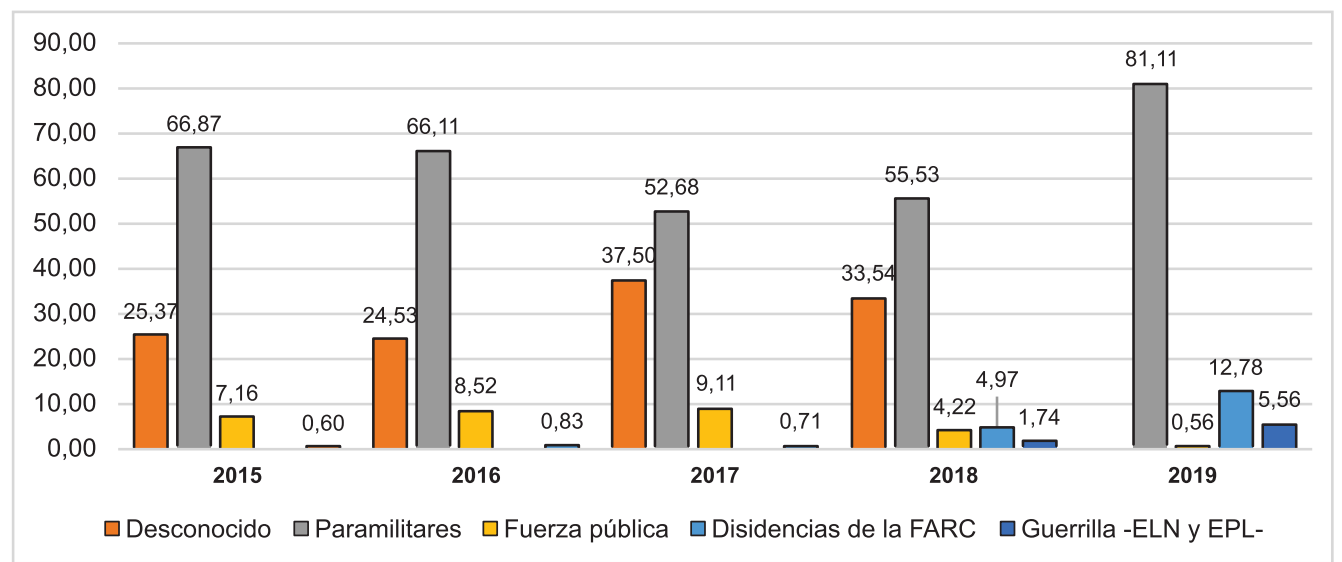

Fuente: Somos Defensores (2017, 2018a, 2018b, 2019a, 2019b). Elaboración propia.

Lo primero que se puede ver en la figura 4 es que, lastimosamente, los asesinatos de líderes y lideresas sociales van en aumento a lo largo del periodo analizado, según datos de Somos Defensores. Los actores del conflicto armado que más asesinatos cometen a líderes sociales son los grupos paramilitares, con un total de 1.664 de estos crímenes.

Lo que sería 'normal' es que los grupos que están al margen de la ley sean los que desarrollen todos los hechos victimizantes contra

7 Un pilar fundamental para pasar la página del oscuro periodo de casi medio siglo de conflicto armado en el país es la restitución de tierras. Ante los incumplimientos del gobierno, y como se ha sugerido a lo largo de este documento, hay personas que se empoderan y abanderan estos procesos para que se haga justicia en estos territorios, desafortunadamente, terminan siendo asesinados. La pregunta que hay por responder, por la justicia en especial, es quién está detrás de estos detestables actos (figura 4). quienes defiendan los intereses de sus comunidades o los derechos humanos. Sin embargo, aún más preocupante es que muchos casos sean llevados a cabo por la fuerza pública, a la fecha se contabilizan 174, y lo más crítico es que es en época del posacuerdo. Así pues, tal como menciona Roth-Deubel (2006), las instituciones que se han creado con el fin de defender a los civiles no cumplen su función, y en algunos casos -como lo evidencia la figura 4- son quienes terminan vulnerando los mismos.

8 Las cifras del año 2019 corresponden al Informe del primer trimestre del 2019 publicado por Somos Defensores. Esta organización no tiene publicado datos de otros trimestres del mismo año.

9 Las disidencias de las FARC empiezan a ser tenidas en cuenta por estos informes como disidencia a partir del 2017, antes figuraban en la misma categoría de "guerrilla". Por ello está en 0 el valor correspondiente para años anteriores. 
De todos los hechos cometidos, los paramilitares ostentan un promedio de $64,46 \%$ de responsabilidad. La práctica de los paramilitares dentro de los distintos conflictos armados -o guerras- es sumamente antiguo, desde colonias francesas en América Latina, con una formación desde Estados Unidos, teniendo una fuerte intención ideológica en la manera de pensar y actuar de las fuerzas armadas de distintos países a lo largo del siglo XX (Velásquez Rivera, 2007). En Colombia, es una herramienta que han usado las élites políticas para mantenerse en el poder, mediante la violencia (García-Peña, 2007, en Velásquez, 2007). García-peña (2007) indica que:

$$
\begin{aligned}
& \text { para obtener y mantener sus } \\
& \text { propiedades y sus privilegios en } \\
& \text { connivencia con el Estado. Los } \\
& \text { antecedentes más cercanos se } \\
& \text { encuentran en los grupos que } \\
& \text { surgieron en la violencia de los } \\
& \text { años cuarenta y cincuenta ... } \\
& \text { (cuando) ... Grupos privados, } \\
& \text { como los denominados Pájaros, } \\
& \text { operaron con el apoyo y la com- } \\
& \text { plicidad de las autoridades (Gar- } \\
& \text { cía-Peña, 2007, pp. 54-56). }
\end{aligned}
$$

Así, se entiende la razón por la que los grupos paramilitares siguen actuando en la afectación de los derechos humanos a los defensores de estos, líderes sociales y las comunidades en el territorio nacional donde han ocurrido los asesinatos. Nada puede justificar esto, y menos cuando en Colombia hay políticos vinculados al fenómeno conocido como 'parapolítica' -políticos que tienen vínculos con grupos paramilitares-. El paramilitarismo como práctica política o de subordinación en Colombia, por el extenso conflicto armado interno, tiene como consecuencia la vulneración de derechos humanos.

Otros dos actores del conflicto armado, situados al margen de la ley, que tienen participación en el asesinato de líderes sociales en el país son las disidencias de las FARC y las guerrillas del ELN y EPL. Aunque son las que menor peso porcentual tienen del total de casos presentados. Es deber del Estado procurar la defensa de los derechos de los líderes sociales y de las comunidades en la periferia del territorio nacional, de las personas que viven en el sector urbano. De todos en general. Con ello, se puede tener una mayor confianza en las fuerzas del orden público.

Sin embargo, es cierto que este tipo de actos le restan confianza y legitimidad a las fuerzas del Estado, como lo menciona Santos Calderon (2019):

Si no respetásemos los derechos humanos, si nos igualáramos a los agentes del narcotráfico y el terrorismo, que no tienen consideración por la vida de los demás, perderíamos nuestro mayor activo operacional, que no son los equipos, ni las tropas, ni las estrategias, sino el apoyo y la confianza de la población.

Un ejército [y en general toda fuerza del Estado] que no se gana con su actitud recta y respetuosa de la comunidad, el apoyo y la confianza del pueblo, es un ejército derrotado de antemano, que ha perdido su razón de ser [...] un ejército que acata la ley y respeta los derechos humanos, tiene consigo la mayor ventaja estratégica posible: la legitimidad. (pp. 135-136). 
Con todo lo anterior, es sumamente preocupante que en distintos momentos de la historia las fuerzas militares hicieran parte del conflicto armado, no defendiendo al Estado -como es su labor-, sino atacando a la población civil, es decir, luchaban a la par con el enemigo, razón por la cual el conflicto tiende a agudizarse en las zonas de conflicto aumentando las incertidumbres que tienen los habitantes de estos lugares. La cita previa hace referencia tanto a las ejecuciones extrajudiciales-conocidos eufemísticamente como 'falsos positivos'-, como a los demás casos de vulneración de derechos humanos por parte de las fuerzas del Estado. Es decir, el enemigo fueron los civiles, en lugar de ser los amigos y protegidos.

\section{Discusión}

Como se ha evidenciado a lo largo del artículo, sigue siendo confusa una conceptualización sobre lo que se entiende por líder social, aunque sí se tiene claro qué categorías lo conforman. Este disenso entre las definiciones del Estado y de las organizaciones es sumamente complejo para las personas, puesto que muchas serán excluidas e invisibilizadas, y se podrían incluir otras que no son líderes o defensores de DDHH -es mucho menos deseable que suceda lo primero-.

Las diferencias entre los conceptos y mediciones que hace el Estado y las organizaciones sociales sobre la vulneración de los DDHH de los líderes sociales y defensores de derechos humanos radican en la visión que cada uno tiene sobre los territorios. Es decir, un líder social y defensor de DDHH actúan según la necesidad que ellos perciben que hay en el territorio. El problema es cuando se hace invisible a la persona que es líder o defiende los derechos humanos. A esto hay que sumarle los hechos demostrados de parapolítica en el país. Si quienes se encargan de escribir y proponer las leyes que protegerán a los líderes sociales y defensores de DDHH son los mismos que tienen vínculos con los grupos que los asesinan, no hay esperanza para que estas personas puedan ser protegidas.

Así las cosas, la antipatía que se presenta desde el Estado es congruente con las relaciones de aquellos políticos aliados con los grupos paramilitares, pero, a juzgar por las cifras, es contagiosa a otras ramas del Poder Público, concretamente con los encargados de investigar estos casos. No solo es importante ver que los grupos paramilitares perpetran estos hechos, sino que todos los que aparecen como desconocidos tengan categoría, que se sepa quién lo hizo y por qué, así estos hechos no se quedan en la impunidad. La protección de los derechos de los líderes sociales no puede simplificarse en un plano simbólico, desde el discurso, debe evidenciarse en acciones concretas que solucionen la problemática de raíz, de forma integral.

Por lo tanto, hay que hablar de diagnóstico, dado que, como se menciona, según el mismo gobierno -especialmente el de Duque, de corte mucho más conservador y de derecha que Santos-, hay un aumento de número de municipios donde se perpetran estos actos, 
pero no hay una política pública visible que quiera solucionarlo, puesto que no es claro que haya un problema como tal. Ni el paramilitarismo, ni las demás causantes de las vulneraciones son tema de discusión en la agenda del gobierno, por ello se dice que no se conoce a los territorios ni sus necesidades, menos a quienes las tramitan.

\section{Conclusiones}

A pesar de que el Estado ha realizado acciones para la defensa y protección de los líderes sociales y defensores de DDHH, estas han sido insuficientes por dos motivos: el primero es la falta de una definición única y amplia sobre estos, ya que la caracterización del problema determina la manera como se plantea su solución. El segundo motivo es que, por la forma que tiene de accionar del Estado, estos 'deberían' estar agrupados en una organización o institución, puesto que el Estado actúa en la medida en que esté organizada la sociedad civil, lo que dificulta la defensa de los líderes ya que no necesariamente deben estar en uno para ser reconocidos como líderes o defensores. Esto último evidencia la razón por la cual no se sabe ni cuántos son ni dónde están, lo que es muestra de la capacidad de acción del Estado ante problemáticas en lo más profundo del territorio nacional.

Además, es necesario tener en cuenta lo que discursivamente se ha dicho desde el gobierno central: la polarización entre 'amigo-enemigo'-el enemigo es el que piensa distinto al statu quo, de forma alternativa, como serían los líderes y defensores de DDHH-, lo cual ha sido consecuencia del conflicto armado interno que vivió el país durante más de medio siglo. Aunque no se quiere dar a entender que los líderes sociales sean miembros de grupos que fueron actores en el marco del conflicto, sino que son víctimas de una polarización por su forma de pensar. Es decir, se tiene el imaginario, de manera desafortunada, que quien piense en hacer distintas acciones con el fin de beneficiar a su comunidad es tildado de pertenecer a la izquierda o ser socialista o comunista, tal como dicen los 'panfletos' con los que los amenazan.

Si bien los líderes sociales no hacen parte de la política tradicional, ni en la forma de hacerla ni en las acciones que les otorgan legitimidad en el territorio, es cierto que este estigma es sumamente perjudicial, puesto que verlos como enemigos desde la perspectiva extremista de la guerra es un pésimo escenario para el desarrollo y la paz de Colombia.

La seguridad, al igual que la educación, el desarrollo, la restitución de tierras y la inequidad son temas que deben ser resueltos por parte del Estado, pues esa es su función. Se dice que solucionar esos problemas es la forma de tramitar puntos importantes del conflicto, por ende, de lograr la paz. La insatisfacción de las personas ha sido caldo de cultivo para que tenga ocasión el conflicto, y, con este, la afectación de los derechos de comunidades enteras, debido a que quedan en medio de enfrentamientos. Esa es la deuda histórica del Estado con su gente la que debe pagarse. 


\section{REFERENCIAS}

Carreras, I., Leaverton, A. y Sureda, M. (2009). Líderes para el cambio social: características y competencias del liderazgo en las ONG. Instituto de Innovación social de ESADE. www.fceer.org/bdoc/recursos/Lideres_para_el_ cambio_social.pdf

Castro Caycedo, G. (2008). El Palacio sin máscara. Editorial Planeta Colombiana.

Chaux, MA. (2007). Más de lo mismo: el espejismo electoral del 2006. En: M.A. Herrera Zgaib, [dir.]. El 28 de mayo y el presidencialismo de excepción en Colombia. Universidad Nacional de Colombia.

Comisión Interamericana de Derechos Humanos -CIDH-. (2019a). Informe sobre la situación de personas defensoras de derechos humanos y líderes sociales en Colombia. http:/www.oas.org/es/cidh/informes/pdfs/ DefensoresColombia.pdf

Comisión Interamericana de Derechos Humanos -CIDH-. (2019b). CIDH expresa su preocupación por asesinatos contra personas defensoras de derechos humanos y líderes sociales durante el primer semestre del año en Colombia. http://www.oas.org/es/cidh/prensa/comunicados/2020/174.asp

Congreso de la República de Colombia. (1997). "Por la cual se consagran unos instrumentos para la búsqueda de la convivencia, la eficacia de la justicia y se dictan otras disposiciones" [Ley 418 de 1997]. www.secretariasenado.gov.co/senado/basedoc/ley_0418_1997.html

Congreso de la República de Colombia. (2011) Por la cual se dictan medidas de atención, asistencia y reparación integral a las víctimas del conflicto armado interno y se dictan otras disposiciones. [Ley 1448 de 2011 ]. www.secretariasenado.gov.co/senado/basedoc/ley_1448_2011.html

Consejería Presidencial para los Derechos Humanos y Asuntos Internacionales. (2019). Informe de homicidios contra líderes sociales y defensores de derechos humanos. www.derechoshumanos.gov.co/Prensa/2019/ Documents/INFORME\%20LDDH\%20ACTUALIZADO\%2017\%20DE\%20 JULIO_V2.pdf

Departamento Administrativo de la Función Pública. (2011). Por el cual se crea la Unidad Nacional de Protección (UNP), se establecen su objetivo y estructura. [Decreto 4065 de 2011]. www.secretariasenado.gov.co/ senado/basedoc/decreto_4065_2011.html

El Espectador. (2011, 7 de mayo). Uribe da 10 razones para no hablar de conflicto armado. www.elespectador.com/noticias/politica/ uribe-da-10-razones-para-no-hablar-de-conflicto-armado/ 
El Espectador. (2019, 12 de agosto). Conflictos por tierra, otra arista en crímenes de líderes sociales. www.elespectador.com/noticias/politica/conflictos-por-la-tierra-otra-arista-en-crimenes-de-lideres-sociales-articulo-875666

El Espectador. (2020, 14 de enero). Al menos 555 líderes sociales han sido asesinados entre 2016 y 2019: Defensoría del Pueblo. www.elespectador.com/noticias/politica/al-menos-555-lideres-sociales-han-sido-asesinados-entre-2016-y-2019-defensoria-del-pueblo-articulo-899826

El Tiempo. (2019, 4 de julio). ¿Cuántos líderes sociales están amenazados en Colombia? www.eltiempo.com/justicia/investigacion/numero-de-lideres-sociales-amenazados-en-colombia-actualmente-384030

Estrada Jopia, C. (2009). Los líderes sociales tienen que ser emprendedores. DPH. http://base.d-p-h.info/es/fiches/dph/fiche-dph-7777.html

Gómez, J. (2018, 12 de diciembre). Líderes de sustitución de cultivos de uso ilícito: en doble riesgo. Paz en el Territorio y El Espectador. https://lapazenelterreno.com/especiales/lideres-sustitucion/

González González, F. E. (2014). Poder y violencia en Colombia. Odecofi-Cinep-Colciencias.

González González, F. E. y Otero Bahamón, S. (2006, 7 de julio). La presencia diferenciada del Estado: un desafío a los conceptos de gobernabilidad y gobernanza. Institut Gourvernance.org. http://www.institut-gouvernance. org/es/analyse/fiche-analyse-237.html

Instituto de Estudios Políticos y Relaciones Internacionales [IEPRI]. (2018). ¿Cuáles son los patrones? Asesinato de líderes sociales en el post acuerdo. Universidad Nacional de Colombia. http://iepri.unal.edu.co/fileadmin/ user_upload/iepri_content/boletin/patrones6.pdf

Indepaz (2020). Líderes sociales y defensores de derechos humanos asesinados en 2020. Indepaz. Consultado el 27 de mayo de 2020. www.indepaz. org.co/paz-al-liderazgo-social/

Indepaz. (2019). Informe parcial Cumbre Agraria Campesina, Étnica y Popular. www.indepaz.org.co/wp-content/uploads/2019/07/Informe-parcial-Julio-26-2019.pdf

Ministerio del Interior y de Justicia. (2000). Por el cual se crea el Programa Especial de Protección Integral para dirigentes, miembros y sobrevivientes de la Unión Patriótica y del Partido Comunista Colombiano. [Decreto 978 de 2000]. www.suin-juriscol.gov.co/viewDocument.asp?id=1731234

Ministerio del Interior y de Justicia. (2006). Por el cual se diseña y reglamenta el Programa de Protección de Derechos Humanos del Ministerio del Interior y de Justicia y se adoptan otras disposiciones. [Decreto 2816 
de 2006]. www.defensoria.gov.co/public/Normograma\%202013_html/ Normas/Decreto_2816_2006.pdf

Ministerio del Interior y de Justicia. (2011). Por el cual se organiza el Programa de Prevención y Protección de los derechos a la vida, la libertad, la integridad y la seguridad de personas, grupos y comunidades del Ministerio del Interior y de la Unidad Nacional de Protección. [Decreto 4912 de 2011 ] www.acnur.org/fileadmin/Documentos/BDL/2014/9983. pdf?file $=$ fileadmin/Documentos/BDL/2014/9983

Navarrete, M. A. y Alonso, L. (2020, 18 de febrero). Radiografía de la violencia contra líderes sociales en Colombia. https://es.insightcrime.org/noticias/ analisis/violencia-lideres-sociales-colombia/

Pacifista. (2019, 11 de febrero). ¿Qué implica que el nuevo director del Centro de Memoria desconozca el conflicto armado? https://pacifista.tv/notas/implicaciones-historicas-decir-pais-no-hay-conflicto-armado-centro-memoria-historica/

Pacifista. (2020, 10 de febrero). Estos son los 277 líderes sociales asesinados desde el inicio de la implementación. https://pacifista.tv/notas/ lideres-sociales-asesinados-inicio-implementacion/

Presidente de la República. (2003). Por el cual se unifica y reglamenta el Comité de Reglamentación y Evaluación de Riesgos de los Programas de Protección de la Dirección de Derechos Humanos del Ministerio del Interior y de Justicia [Decreto 2788 de 2003]. www.suin-juriscol.gov.co/ viewDocument.asp?id $=1490743$

Ramírez León, L. (2017, 2 de noviembre). “Un líder social o un defensor de DD.HH. es un tejedor de voluntades”: Carlos Guevara. ONIC. www.onic. org.co/comunicados-de-otros-sectores/2200-un-lider-social-o-un-defensor-de-dd-hh-es-un-tejedor-de-voluntades-carlos-guevara

Rojas, C. E. (2001). Los derechos humanos en Colombia: tensiones entre sociedad y Estado. Virajes, Estado y gobernabilidad. 3(1). http://vip.ucaldas. edu.co/virajes/downloads/Virajes3(1)_4.pdf

Roth-Deubel, A-N. (2006). Discurso sin compromiso: la política pública de derechos humanos en Colombia. Ediciones Aurora.

Salazar, S \& Gómez, LF. (2019, 29 de enero). Explicador: ¿qué es un líder social? Colombia Check. https://colombiacheck.com/investigaciones/ explicador-que-es-un-lider-social

Santos Calderón, J.M. (2019). La batalla por la paz: el largo camino para acabar el conflicto con la guerrilla más antigua del mundo. (2ed.). Editorial Planeta Colombiana 
Semana Rural. (2019, 12 de agosto). "A los líderes sociales los asesinan por la tierra, no por el narcotráfico": Forjando Futuro. https://semanarural.com/ web/articulo/a-los-lideres-sociales-los-asesinan-por-problemas-de-tierras-no-por-el-narcotrafico-forjando-futuros/1079

Somos Defensores. (2017). Contra las cuerdas: Informe anual 2016 Sistema de Información sobre Agresiones contra Personas Defensoras de Derechos Humanos en Colombia. https://somosdefensores.org/wp-content/ uploads/2018/08/Documentos/TODOS\%20LOS\%2OINFORMES/informes\%20en\%20espa\%C3\%B 1 ol/informes\%20anuales/INFORME\%20 SOMOS\%2ODEFENSORES\%202016\%20ANUAL_ESPA\%C3\%91OL.pdf

Somos Defensores. (2018a). Más allá de las cifras. Segunda parte. Informe enero-junio 2018: Sistema de Información sobre Agresiones contra Personas Defensoras de Derechos Humanos en Colombia. https://somosdefensores. org/wp-content/uploads/2018/09/MasAllaDeLasCifrasEspWeb.pdf

Somos Defensores. (2018b). Piedra en el zapato: Informe anual 2017 Sistema de Información sobre Agresiones contra Personas Defensoras de Derechos Humanos en Colombia. https://somosdefensores.org/wp-content/ uploads/2019/05/INFORME-SOMOS-DEFENSORES-2017-ANUAL_ESPAN\%CC\%83OL.pdf

Somos Defensores. (2019a). Boletín trimestral Sistema de Información sobre Agresiones contra Personas Defensoras de Derechos Humanos en Colombia. Enero-marzo 2019. https://somosdefensores.org/wp-content/ uploads/2019/04/boletin-SIADDHH-enero-marzo-2019.pdf

Somos Defensores. (2019b). La Naranja Mecánica: Informe anual 2018 Sistema de Información sobre Agresiones contra Personas Defensoras de Derechos Humanos en Colombia. https://somosdefensores.org/wp-content/ uploads/2019/04/informe-somos-defensores-2019-espanol-web.pdf

Velásquez Rivera, E. J. (2007). Historia del paramilitarismo en Colombia. Historia, São Paulo. 26(1). Pp. 134-153. http://dx.doi.org/10.1590/ S0101-90742007000100012.

Weber, M. (1979). El político y el científico. Alianza Editorial. 